\title{
PINTURAS MURALES DE ERNESTO ICAZA
}

\author{
Por Xavier Moyssén
}

Tanto por los temas como por los tipos que eligió para expresarse, Ernesto Icaza (1866-1935) es un artista que posee una personalidad propia en la historia de la pintura mexicana. Atendiendo al número de cuadros que pintó y a la originalidad que puso en ellos, la obra artística de Icaza resulta de un valor considerable, máxime cuando sus pinturas muestran, con gran propiedad, aspectos de lo que era la vida en el campo mexicano; pues él fue, por antonomasia, el pintor de los charros y sus costumbres. Todos los aspectos que dan vida y color a los charros, asf como sus vistosas y temerarias actividades ya en ranchos y haciendas, $o$ en los coleaderos y jaripeos, Ernesto Icaza con atinada disposición supo retenerlos en las obras que salieron de sus pinceles. No hubo escena de la vida campirana que escapara a su inspiración. El mismo era un habilísimo charro y ello contribuyó, como bien dice Justino Fernández, para que "las costumbres del campo entre hacendados y rancheros y, sobre todo, el arte de charrear, encontrara en Icaza su más genuino intérprete." 1

No es el caso ocuparnos, en esta ocasión, de las pinturas de caballete de Ernesto Icaza, ya otros autores lo han hecho y a sus trabajos debe acudir el lector interesado. ${ }^{2}$ SI vamos a ocuparnos, en cambio, de las pinturas murales que el charro-pintor ejecutó en la hacienda de $L a$ Cofradia.

La hacienda de La Cofradia está situada en las inmediaciones del histórico pueblo de Aculco, en el Estado de México. Su existencia debe datar, posiblemente, de las postrimerías de la Colonia, si no es que surgió en el siglo xix, a la sombra del enorme latifundio que fue la cercana hacienda de Arroyo-Zarco, pues las construcciones levantadas en el casco de La Cofradia corresponden al tipo de finca campestre

1 Justino Fernández. Arte Moderno y Contemporineo de México. Instituto de Investigaciones Estéticas. U.N.A.M. México, 1952, p. 432.

2 Consúltese el libro citado de Justino Fernández, y el artículo de Ceferino Palencia: "Los charros pintados por Ernesto Icaza, G. Morales y otros artistas". Artes de México, Núm. 26, vol. v. Año vif. México, 1959. Véase también el breve texto que Fernando Gamboa escribió para presentar la exposición de la obra del artista, en 1950, en el Museo Nacional de Arte Moderno. 
del siglo pasado, Rodeada de extensas llanuras con pastizales, La Cofradia estuvo dedicada a la cría de ganado bovino. Como dato curioso anotaremos que la hacienda perteneció a don Macario Pérez Romero, y que en ella nació su hija Sara, posteriormente esposa de don Francisco I. Madero.

En los corredores que rodean el patio principal de la casa mayor de la hacienda, Ernesto Icaza pintó a lo largo de varios años, nueve grandes murales al oleo. Las fechas de ejecución obedecen a las diversas y espaciadas visitas que el artista hizo al lugar; esas fechas son las siguientes: 1910, 1916, 1920 y 1923; mas es necesario anotar que no obstante la diferencia de años, todas las pinturas guardan entre si una perfecta unidad en su estilo. En alguno de los murales Icaza contó con un ayudante, quien se firmaba J. Rodríguez; nada más sabemos respecto a él, tal vez no fue más que un simple aficionado, por lo menos es lo que muestran tres murales suyos que alternan desfavorablemente con los de Icaza, pues son horrendas copias de paisajes "a la europea", sacados de tarjetas postales; las pinturas en que debió ayudar a Icaza, son las que corresponden a las figuras 4 y 5 , por lo menos en ellas su presencia es más notable.

El tema de las pinturas murales de Icaza, como no podía ser menos en él, es la vida propia de la hacienda y las múltiples actividades que en ella tienen Iugar; el movimiento y el colorido pintoresco de las faenas y distracciones de los charros y peones, fueron captados con esa maestría de que Icaza era capaz. El paisaje que sirve de fondo a estas pinturas está tomado, ni más ni menos, de la propia región en que está situada la hacienda; aunque, como es lógico suponer, Icaza al interpretarlo introdujo algunas modificaciones.

Como en toda pintura mural, en las de este artista hay trozos que son magníficos; por el aplomo con que plantó a sus figuras, por la limpieza que hay en sus colores y el firme trazo de sus dibujos y asimismo, por la propiedad del movimiento dinámico, puesto en algunas escenas que logran emocionar al espectador. Como ejemplos de lo antes dicho, señalamos los siguientes: un buen detalle de colocación y trazo en el dibujo, es el jinete que aparece montando un caballo blanco, en la figura 2. Su pericia queda de manifiesto en el movimiento que supo imprimir a la escena en la que un charro monta a "pelo", a un brioso corcel; y lo mismo puede decirse de la pintura Lazando en el campo, figuras 1 y 3.

Respecto a Ernesto Icaza siempre hemos sospechado que no es el artista autodidacta que de él se ha pretendido hacer; no aceptamos más 
el que haya sido un simple "espontáneo" en la pintura, ni mucho menos. Esto lo hemos meditado anteriormente ante sus pinturas de caballete y hoy, ante la vista de sus murales de $L a$ Cofradía, podemos asegurar que Ernesto Icaza, el charro-pintor, tuvo, por lo menos, una mediana enseñanza del arte de la pintura; para ello no debió pasar forzosamente por la Academia de San Carlos, en cuyos registros de alumnos lo hemos buscado infructuosamente, por lo menos en los años en que debió asistir. El bien pudo haber estudiado en cualquier taller fuera de la Academia y aún en alguna ciudad de la provincia.

Que Ernesto Icaza no fue un artista autodidacta, ni puramente intuitivo y sin escuela, nos lo demuestra él mismo con la calidad existente en buen número de sus pinturas de caballete y aún en estos murales de La Cofradia. Sin embargo, es necesario advertir y refrenar el vuelo fácil del entusiasmo, para decir que es en las figuras de caballos y reses donde Icaza muestra una mayor desenvoltura y seguridad, que no así en la figura humana; cuando se ocupa de los charros atareados en múltiples suertes, sus figuras no pueden ser más adecuadas a esa realidad, pero no acontece asf, casi por regla general, cuando los presenta en otras actividades o actitudes, en estos casos el artista deja mucho que desear.

Estas pinturas que hoy damos a conocer, parece que no fueron las únicas que sobre muros hiciera este artista. Se dice que en la finca de la hacienda Ciènega del Rincón, o de Mata, Icaza pintó sobre los muros otras pinturas similares; si bien el Marqués de San Francisco, don Manuel Romero de Terreros, asegura no haberlas visto jamás. ${ }^{3}$ No obstante, es posible que si no en la hacienda de Ciénega del Rincón, sí en otras, de sus amigos personales existan pinturas suyas; pues fue una costumbre y un lujo el decorar así los grandes corredores de las viejas haciendas mexicanas durante el porfirismo y qué fortuna para los propietarios de las mismas, si podían contar con la calidad de un artista como Icaza. No está de más el recordar aquí, las pinturas que en los muros de la hacienda El Burro de Oro, en la Barca, Jalisco, hiciera Gerardo Suárez. ${ }^{4}$ En fecha reciente el investigador Jorge Olvera ha dado a conocer un buen número de fincas pulqueras del Estado de Hidalgo, en las cuales existen grandes decoraciones murales alusivas al cultivo

3 La noticia de estos murales la ofrece Ceferino Palencia, en el artículo citado en la nota anterior. La negación del Señor Marqués proviene de una consulta hecha por el autor.

4 Raúl Flores Guerrero. "Los muralistas del siglo xrx". Artes de México. Núm. 4 México, 1954. 
y explotación del maguey. ${ }^{6}$ La práctica de la pintura mural fue fomentáda, a su manera y con sus consiguientes limitaciones, por los terratenientes del régimen porfirista, para lo cual se prestaron los propios artistas de la Academia, al ocuparse en pintar, incluso, las pulquerías de la ciudad de México, tal como acontece hoy día en que los pintores son llamados a decorar las tiendas comerciales. 6

La pintura mural en México ha tenido una continuidad histórica ininterrumpida, en su práctica, desde los tiempos precolombinos; estos murales de Ernesto Icaza, iniciados en 1910 y concluidos en 1923, forman parte de esa continuidad. $Y$ curiosamente por una pura coincidencia de tiempo y espacio, mientras él trabajaba en La Cofradia, Diego Rivera, José Clemente Orozco, David Alfaro Siqueiros y otros artistas, habían creado ya con grandes obras, la pintura mural del México contemporáneo. ${ }^{7}$

6 Jorge Olvera. "Ciudad Sahagún y sus alrededores" Artes de México. Núms. 56-57. México, 1964.

- A Manuel-Francisco Alvarez, debemos estas interesantes noticias sobre los pintores académicos del siglo xix: "Monroy (Petronilo) obtuvo por oposición con Ramón Sagredo y Fidencio Vega, la clase de ornato en la Academia de San Carlos, y se dedicó a los trabajos de decoración, decorando en compañia de sus condiscípulos José Obregón, las casas del general don Manuel González. También pintó en varias pulquerias que como comercio lucrativo por la protección del público, daban albergue a las bellas artes, en general tan despreciadas. En la pulquería de la esquina de las. calles de Balvanera y Jesús puede conocerse todavia en las puertas de la calle, la mano de otro artista, de nuestro inolvidable Ramón Rodríguez Arangoity, que proyectó $\dot{y}$ dirigió la obra de carpintería, asł como Monroy se encargó de la pintura y decoración interior. En otras pulquerías del rico empresario Garnica, pintó Monroy para una el cuadro El Amor Cautivo y en otra La Fuente Embriagadora, en la calle de Tacuba. Los trabajos de Monroy no fueron del agrado de sus compañeros los profesores de la Academia, y quien sabe que ideas absurdas se les ocurrieron, teniéndole muy a mal que pintara para las pulquerías creyendo que así desprestigiaba al arte y los artistas. Hubo otro pintor discípulo de Clavé, Pedro Guadarrama, que se dedicó a la decoración y que decord varias pulquerias. Actualmente (1914) hasta el recurso de la decora. ción de aquellas ha desaparecido para el artẹ..." Vide Las pinturas de la Academia de Bellas Artes. Su mérito artistico y su valor comercial. México, 1917. pp. 12-14.

7 Las fotos de los murales de Ernesto Icaza; fueron tomadas expresamente por

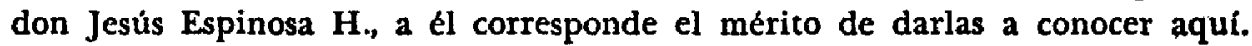




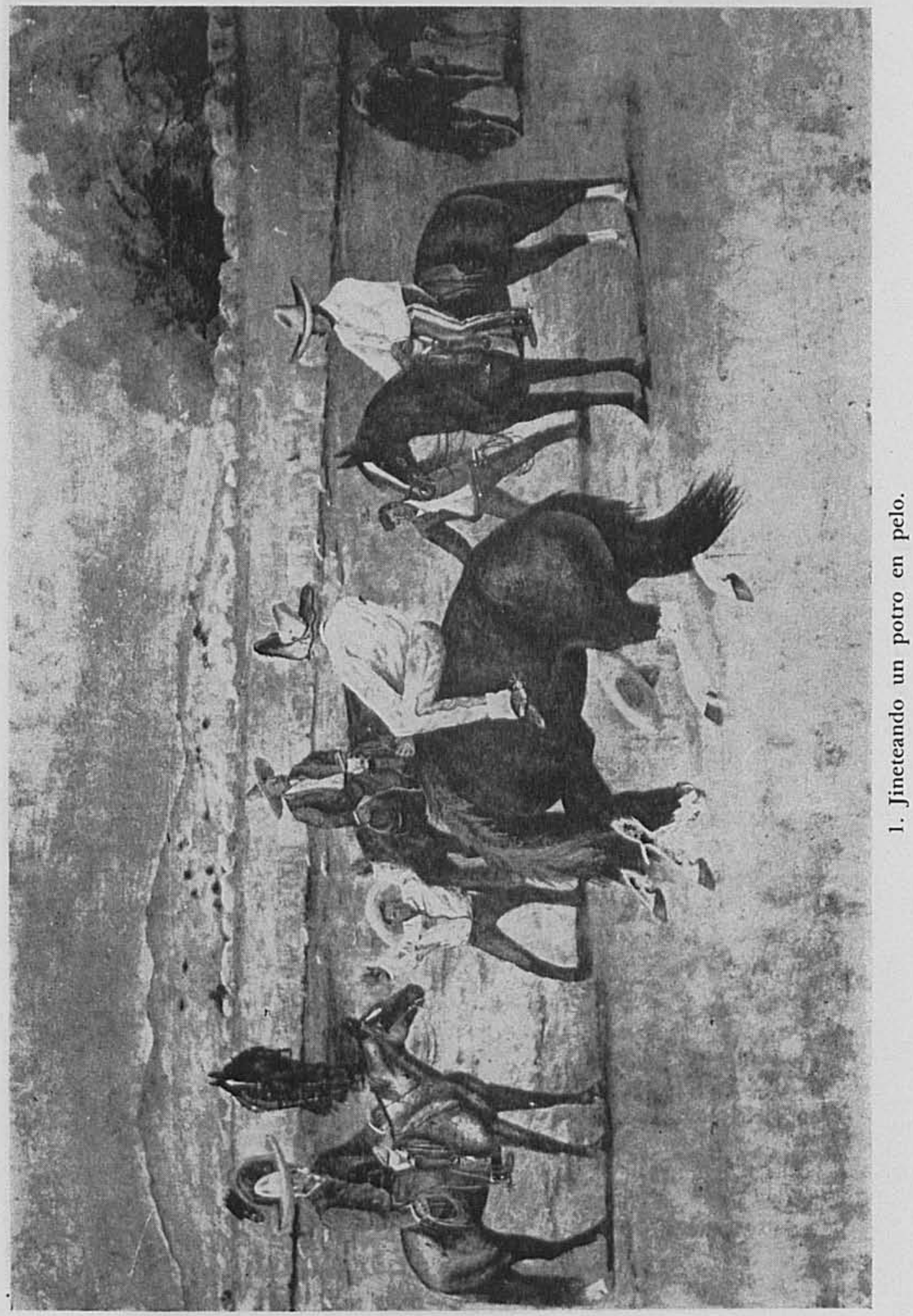


DOI: http://dx.doi.org/10.22201/iie.18703062e.1965.34.793

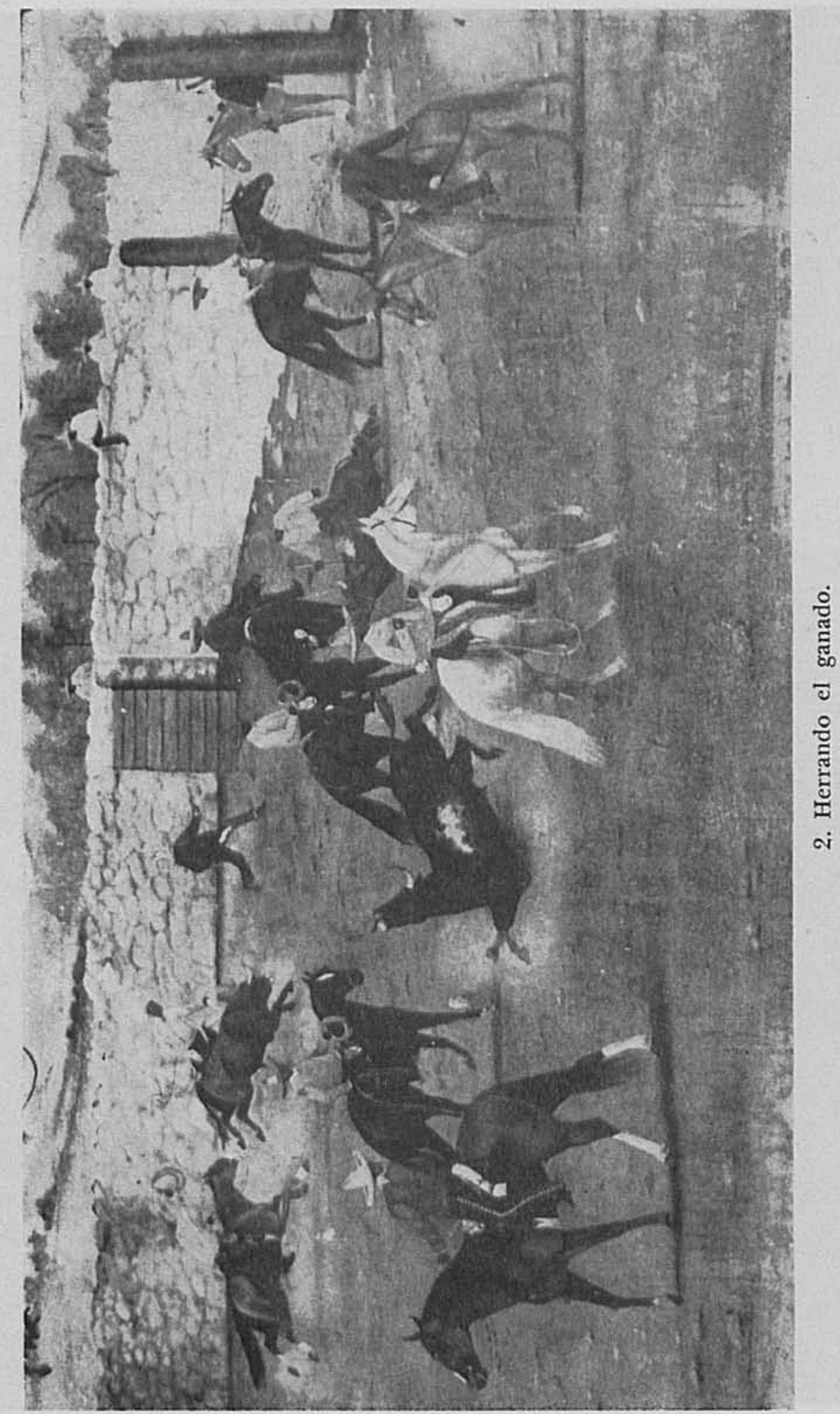




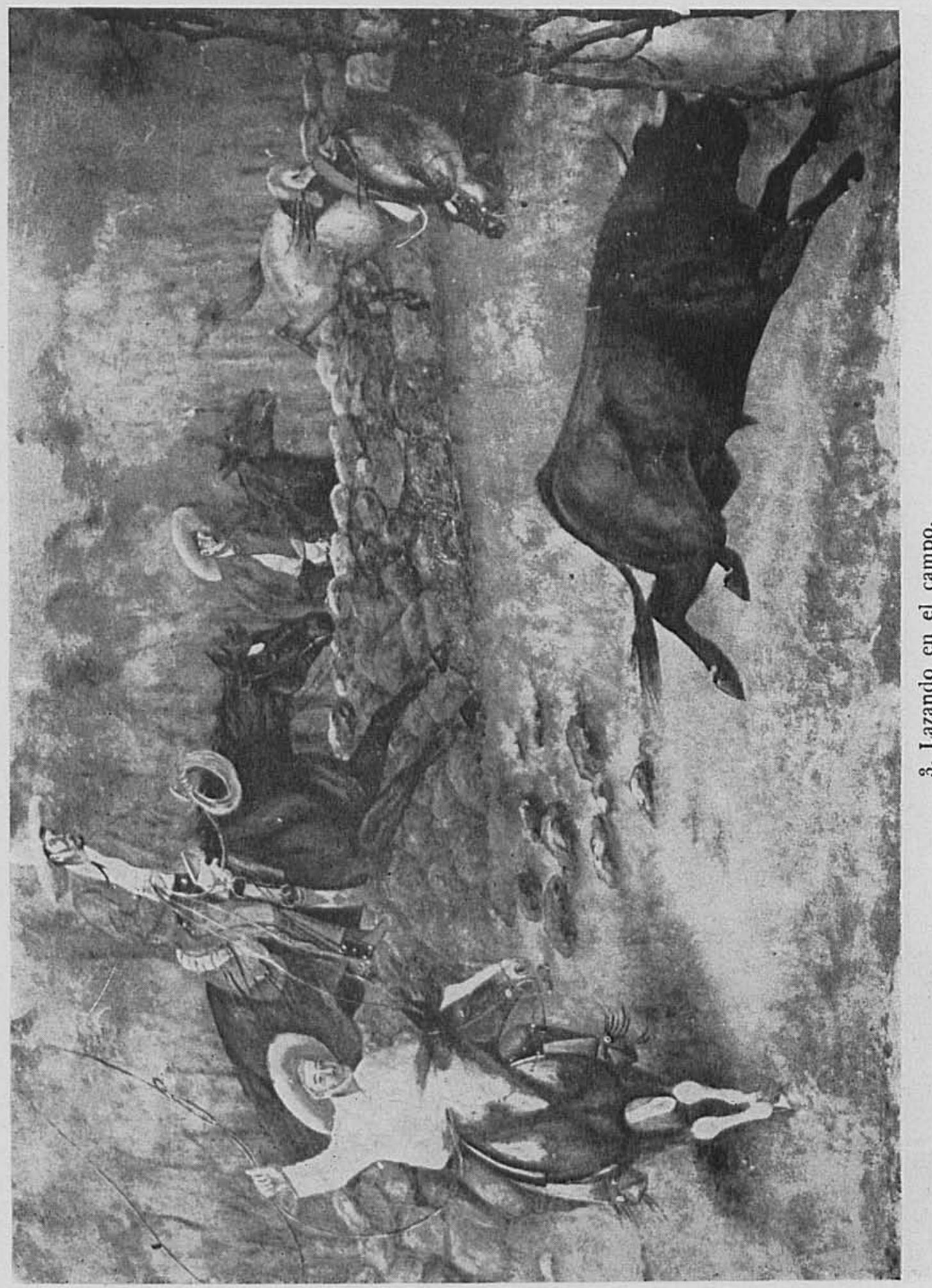


DOI: http://dx.doi.org/10.22201/iie.18703062e.1965.34.793

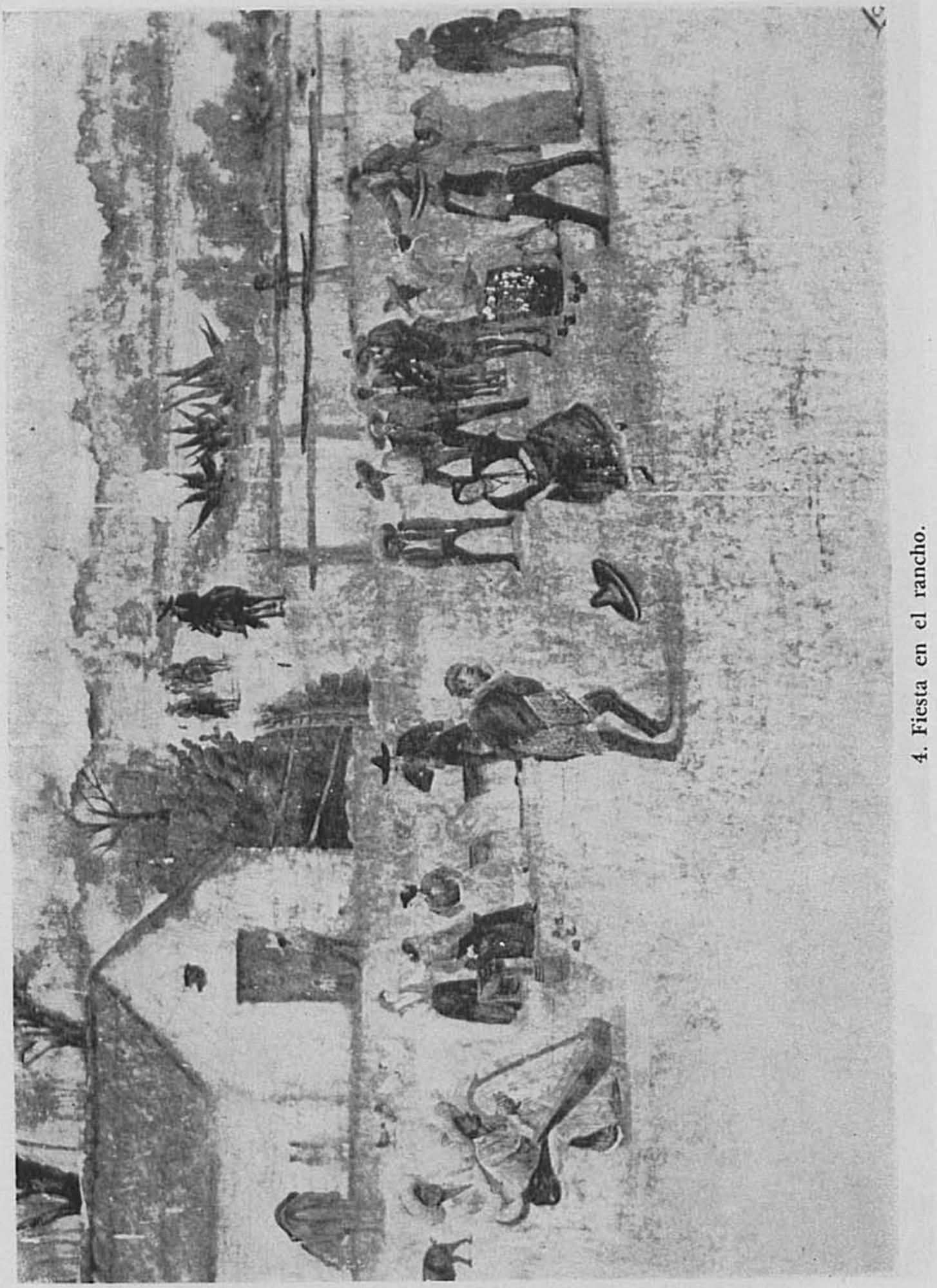




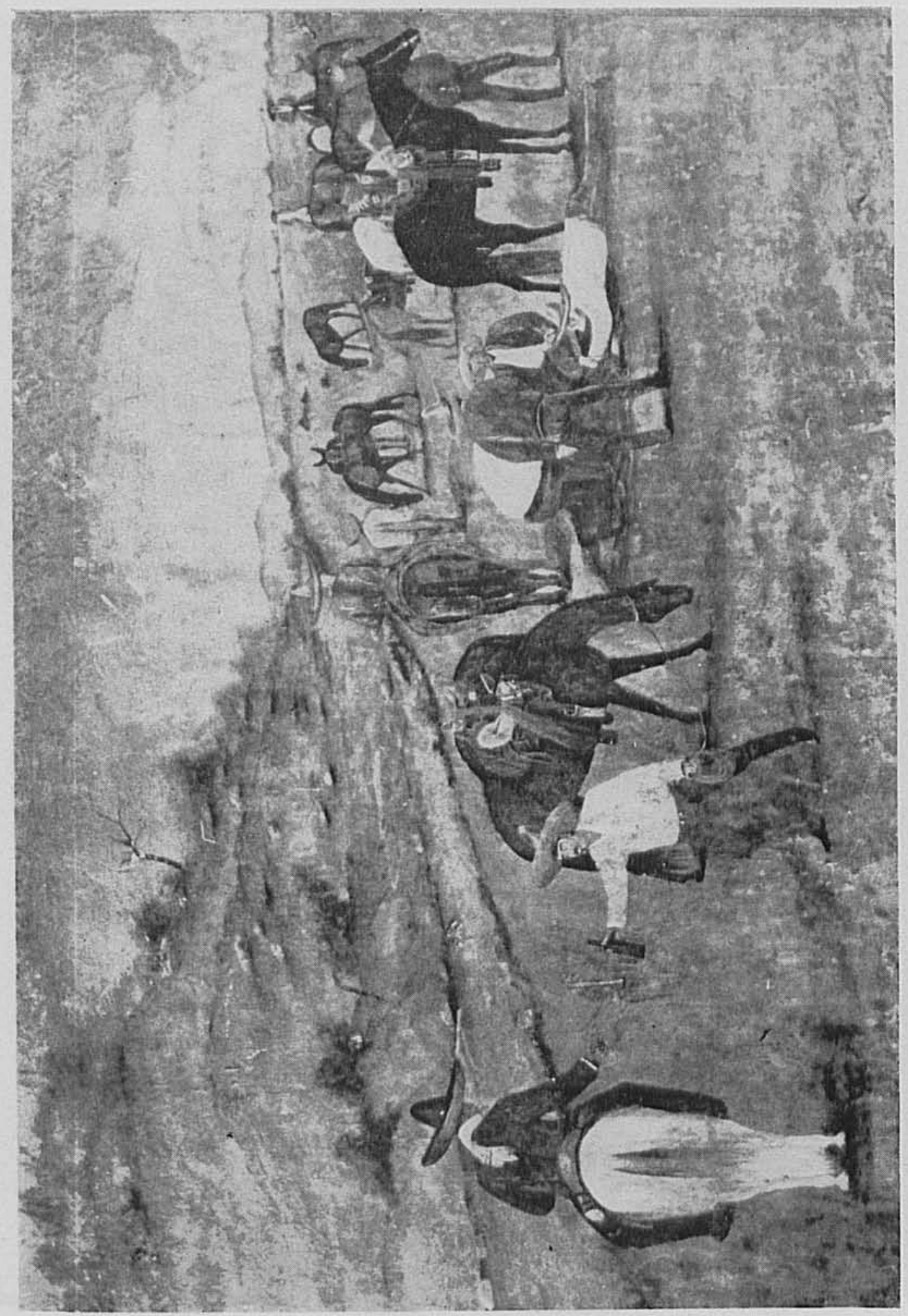




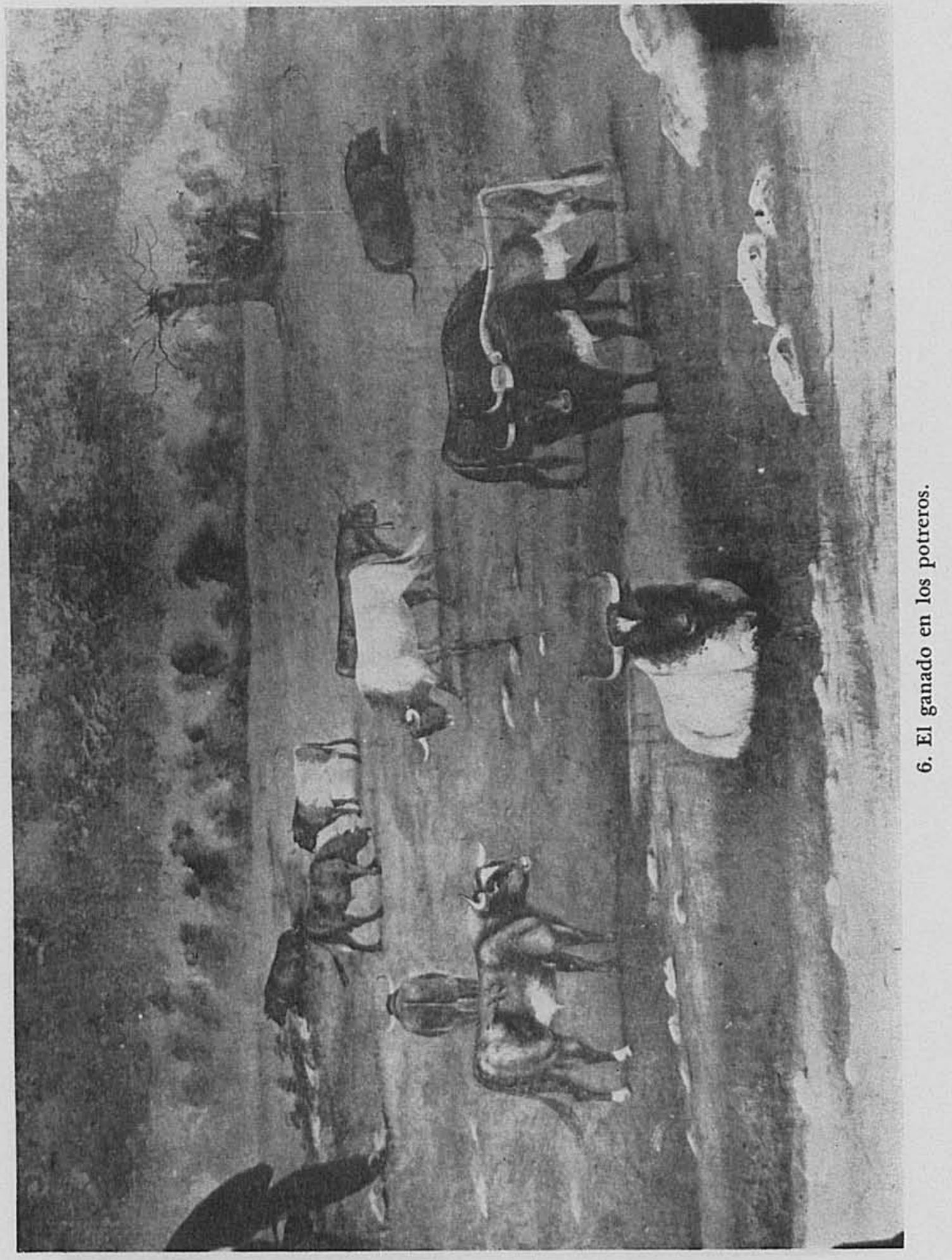




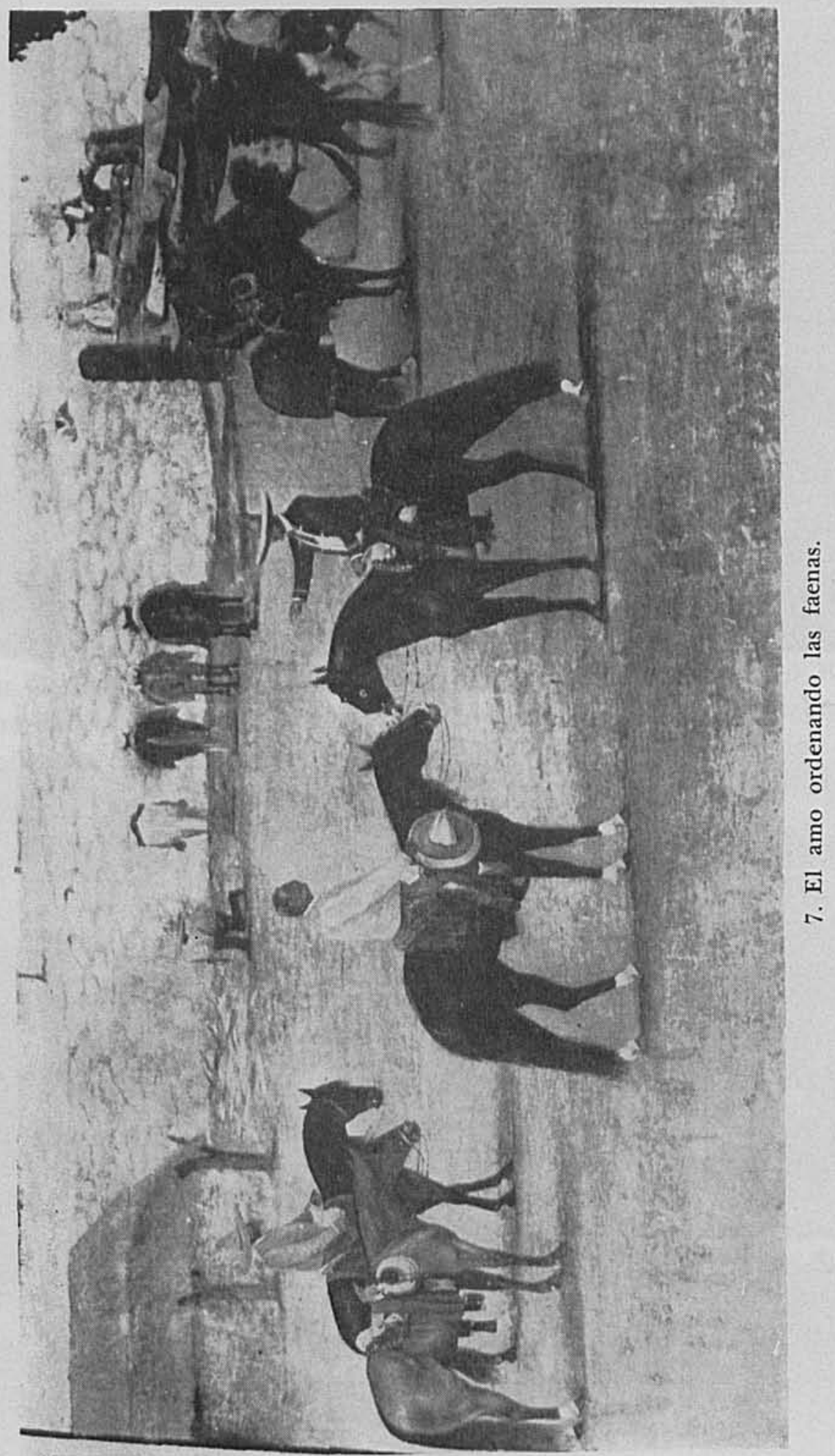




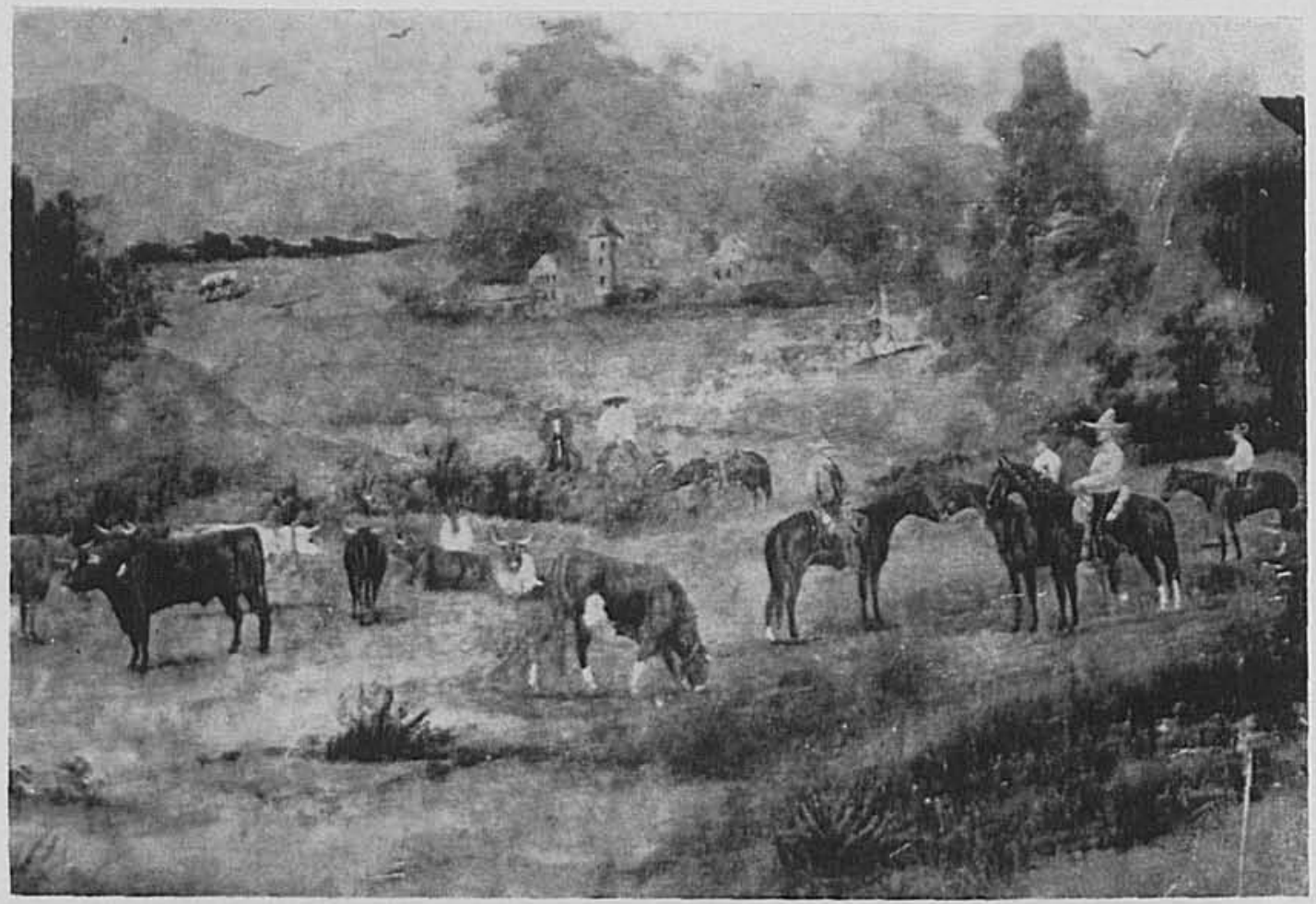

8. Recorriendo la hacienda.

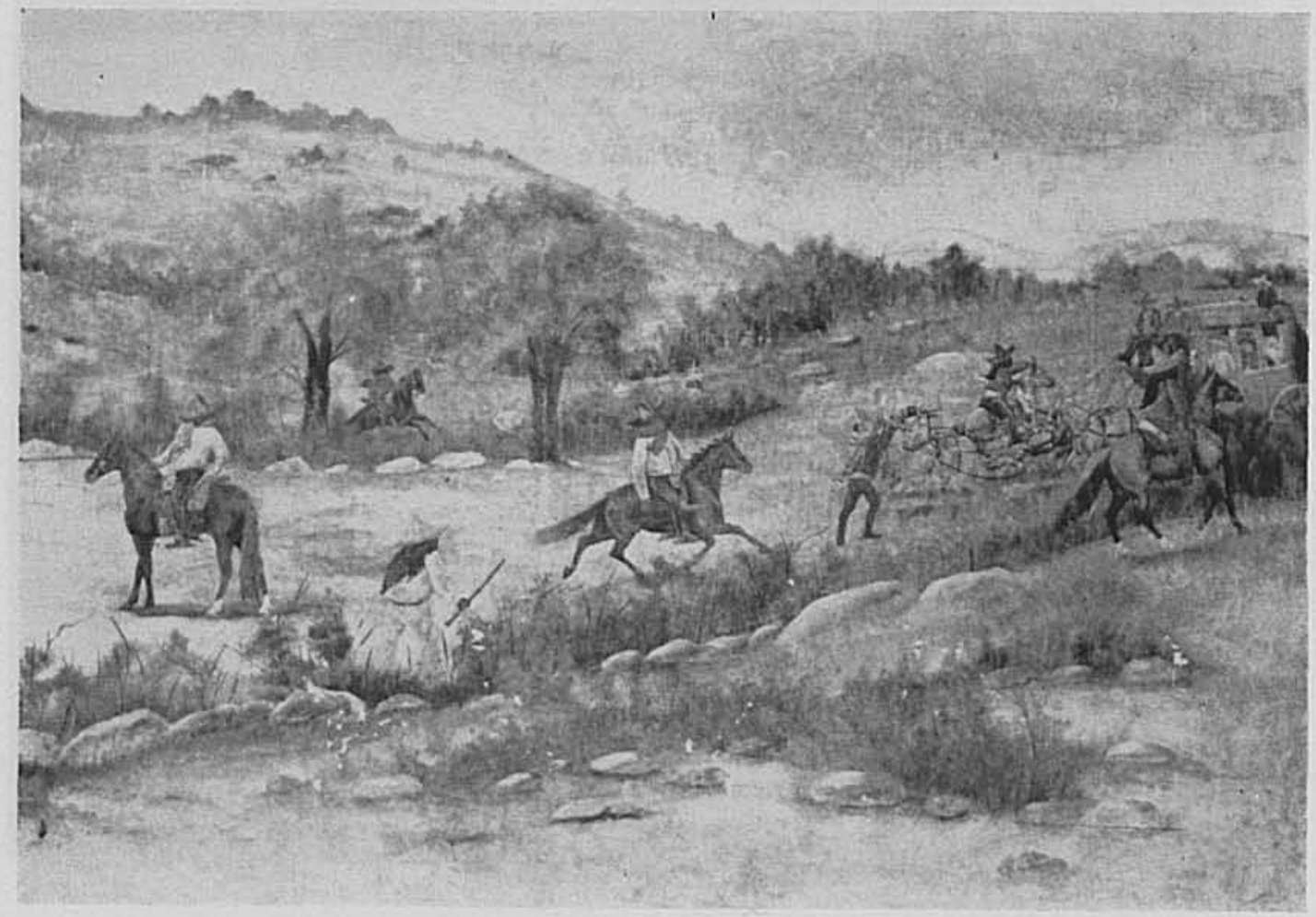

9. Asalto a una diligencia. 